\title{
Violations of dominance in decision-making
}

\author{
Thomas Kourouxous ${ }^{1} \cdot$ Thomas Bauer $^{2}$
}

Received: 4 December 2017/Accepted: 26 February 2019/Published online: 18 March 2019

(C) The Author(s) 2019

\begin{abstract}
A key premise underlying most of the economic literature is that rational decision-makers will choose dominant strategies over dominated alternatives. However, prior literature in various disciplines including business, psychology, and economics document a series of phenomena associated with violations of the dominance principle in decision-making. In this comprehensive review, we discuss conditions under which people violate the dominance principle in decision-making. When presenting violations of dominance in empirical and experimental studies, we differentiate between absolute, statewise, and stochastic (first- and second-order) violations of dominance. Furthermore, we categorize the literature by the leading causes for dominance violations: framing, reference points, certainty effects, bounded rationality, and emotional responses.
\end{abstract}

Keywords Decision theory - Absolute dominance - Statewise dominance * First-order stochastic dominance $\cdot$ Second-order stochastic dominance

\section{Introduction}

The principle of dominance "is perhaps the most obvious principle of rational choice" and serves as the cornerstone of decision theory. ${ }^{1}$ If a decision set contains a dominant strategy, a rational decision-maker should always select the dominant

\footnotetext{
${ }^{1}$ See Kahneman and Tversky (1986).

Thomas Kourouxous

thomas.kourouxous@upb.de

1 Department of Taxation, Accounting and Finance, University of Paderborn, Warburger Straße 100, 33098 Paderborn, Germany

2 Department of Accounting and Managerial Control, University of Vienna, Oskar-MorgensternPlatz 1, 1090 Vienna, Austria
} 
strategy over its dominated alternative, since violations of this principle result in situations in which the decision-maker is ex ante worse off. While dominance is a generally accepted principle in decision theory, violations thereof have been documented in various disciplines such as management, economics, finance, psychology, or health science. Violations of the dominance principle are as old as the normative principle itself. In the third century AD, Arnobius the Elder, a scholar from Sicca, argued that Christianity is the dominant alternative in a $2 \times 2$ decision matrix involving religious choice and the existence of God. If God does not exist, there is no difference between the alternatives, but if God exists being Christian is dominant compared to being pagan. ${ }^{2}$ In the early days of decision-making theory, scholars assumed that human choice always follows descriptive norms. According to this view, violations of dominance are random errors that need no further consideration. Eventually, scholars acknowledged that simple expected value maximization is not appropriate to capture rational decision-making, for instance as the utility of money is non-linear. ${ }^{3}$ Adding structure to this phenomenon, terms such as risk-aversion were introduced followed by a systematic analysis of stochastic dominance in the modern economics and finance literature. ${ }^{4}$

Observed violations of dominance in empirical and experimental research have been key to the evolution of decision theory. For instance, they led to the realization that preferences influence decision-making that were subsequently incorporated into early decision theory frameworks. Various decision paradoxes such as of Allais, Ellsberg, and St. Petersburg paved the way for further amendments by showing that rational choice is not always in line with the premises of expected as well as subjective utility theory. ${ }^{5}$ In an iterative process, more comprehensive decision theories such as the rank-dependent expected utility, prospect and cumulative prospect theory were developed to account for successively emerging decision paradoxes.

Our paper reviews recent empirical and experimental literature with respect to violations of dominance in decision theory. We identify the most common causes for violations of dominance, namely framing, reference points, certainty effects, bounded rationality, emotional responses, the "less-is-more" effect, and the "peakend" rule. In accordance with those common causes, we group the reviewed studies into separate sections. We document that framing, i.e., the description and presentation of a decision problem, strongly influences the decision-maker's choices. Both, the way outcomes are described and the way alternatives are presented, can influence a decision-maker into choosing a dominated alternative. Furthermore, reference points, a form of prior expectations every decision-maker

\footnotetext{
${ }^{2}$ See Covello and Mumpower (1985).

${ }^{3}$ Daniel Bernoulli theorized that the utility of money is non-linear in 1738. See e.g., Wakker (1993) or Birnbaum (2001).

${ }^{4}$ For decision-making under uncertainty, the stochastic dominance principle can be traced back to the work of Jakob I. Bernoulli published in 1713. For an exhaustive research bibliography regarding decisions under uncertainty and stochastic dominance in finance, economics, mathematics, operations research and statistics up until 1982, see Bawa (1982).

${ }^{5}$ For instance, in the St. Petersburg paradox, decision-makers prefer small but certain money over a gamble with infinite expected value. See e.g., Birnbaum (1998).
} 
has when confronted with a decision problem, influence the evaluation of outcomes and ultimately choice itself. In other words, the decision-maker considers some salient value as neutral and compares the outcomes of all alternatives with this reference point. Another source for violations is the human tendency of decisionmakers to overweigh the value of certainty. We document various situations in which decision-makers are willing to pick dominated alternatives to avoid randomness. Furthermore, we document that bounded rationality plays an important role in human decision-making. When the decision-maker is unable to comprehend all information necessary for a coherent decision, she will resort to shortcuts and heuristics. ${ }^{6}$ Similarly, emotions impact decisions by influencing preferences, triggering ad hoc heuristics or causing attention shifts to catastrophic outcomes.

Dominance violations can broadly be looked at in one of two ways. On the one hand, decision-makers violate the dominance principle unintentionally whenever the decision problem is too complex or when the dominance relation is "masked". On the other hand, decision-makers may choose a dominated alternative intentionally due to individual preferences or as an emotional response. In the absence of truly knowing if the dominance principle was "intentionally" violated, researchers resort to thresholds in excess of which violations are being considered as significant for decision theory. Interestingly, there is dissent among researchers relative to what (frequency) constitutes a systematic violation of dominance that can be meaningful for describing human choice. While authors in some studies regard dominance violation rates in the low double digit percentage range as worthwhile discussing, in other studies, authors only report and discuss dominance violation rates which are well above $50 \%{ }^{7} \mathrm{We}$ are concerned with violations of dominance that are due to some meaningful phenomenon, and are thus more than statistical noise. If backed by theory, we believe that any documented deviation from the dominance principle can be of importance.

To the best of our knowledge, there is no prior literature review specifically addressing violations of dominance. Closely related is Levy (1992) who provides a comprehensive review on stochastic dominance with emphasis on developments in the 1980s, Seidl (2002) who reviews preference reversals, and Yacub et al. (2009) who list various decision biases that are not in line with expected utility theory.

Our paper proceeds as follows. In Sect. 2, we define the most common forms of dominance in decision theory. In Sect. 3, we discuss the impact of decision framing on violations of dominance. In Sect. 4, we document violations of dominance associated with reference points. We proceed with violations of dominance associated with certainty in Sect. 5. In Sect. 6, we look at studies that document violations of dominance associated with bounded rationality of decision-makers. Subsequently, we discuss studies that document dominance violations as a result of emotional influences and experiences in Sect. 7. Finally, we contemplate the "lessis-more" effect and the "peak-end" rule in Sect. 8 before concluding the paper with

\footnotetext{
6 Throughout the paper, we refer to the decision-maker as she.

7 For example, the violations rates discussed in Starmer (1999) are significantly lower than in Levy (2008) or Birnbaum (2007).
} 
some concluding remarks. A table at the end of each section provides an overview of all discussed studies.

\section{Forms of dominance}

In this article, we differentiate between four forms of dominance. For convenience, we briefly define these concepts beginning with absolute dominance followed by statewise dominance, first-order stochastic dominance, and concluding with secondorder stochastic dominance. We say that alternative $a$ dominates alternative $b$ by absolute dominance if the worst outcome of alternative $a$ is not lower than the best outcome of alternative $b$,

$$
\min x_{a} \geq \max x_{b},
$$

and the alternatives are not identical. ${ }^{8}$ Absolute dominance is a rather strong condition, thus violations of absolute dominance in empirical or experimental research are rather infrequent. ${ }^{9}$ Absolute dominant alternatives can even be recognized as dominant by cognitively limited agents as the agent does need to compare the outcomes for each contingency. ${ }^{10} \mathrm{~A}$ weaker condition that depends on the realization of the environment is statewise dominance. Statewise dominance requires the outcomes of alternative $a$ to be at least as good as the outcomes of alternative $b$ in all states $\mathrm{S}=\{1,2, \ldots, \mathrm{N}\}$ and strictly better in at least one state $s$ :

$$
\forall s \in S: x_{a, s} \geq x_{b, s} \quad \text { and } \quad \exists s \in S: x_{a, s}>x_{b, s} .
$$

The literature often does not differentiate between absolute and statewise dominance and simply speaks of dominance. ${ }^{11}$ Occasionally, dominance and terms such as rationality, monotonicity, and pareto-optimality are used contextually interchangeably. ${ }^{12}$ In the presence of risk and uncertainty, we refer to the term stochastic dominance to describe the relation between alternatives such that for any outcome, given a chosen alternative, the probability of a lower outcome, is less than or equal to all other alternatives. ${ }^{13}$ In the following, we formally differentiate between firstorder and second-order stochastic dominance. ${ }^{14}$ An alternative $a$ dominates an alternative $b$ by first-order stochastic dominance, if for every possible outcome

\footnotetext{
8 For example, see page 98 in Laux et al. (2014).

9 See Keys and Schwartz (2007).

${ }^{10}$ See Li (2017). He discusses the closely related concept of obvious dominance which is used to describe strategies in games.

11 See for example, Li (2001).

${ }^{12}$ Luce and von Winterfeldt (1994) decompose the principle of dominance into outcome and event monotonicity. Amiel and Cowell (1993) discuss similarities and differences related to the application of those concepts to economics.

13 See also Birnbaum and Thompson (1996). Early theoretical work in economics on stochastic dominance can be traced back to Rothschild and Stiglitz (1970).

14 For a discussion of other forms of stochastic dominance see Levy and Levy (2002) and Wakker (2003).
} 
level, the probability of achieving that outcome with alternative $a$ is at least as high as with alternative $b$, and for at least one outcome level, it is strictly higher:

$$
\forall x: \mathbb{P}\left(x_{a} \geq x\right) \geq \mathbb{P}\left(x_{b} \geq x\right) \text { and } \exists x: \mathbb{P}\left(x_{a} \geq x\right)>\mathbb{P}\left(x_{b} \geq x\right) .
$$

This implies that the expected value of the dominant alternative cannot be lower than the expected value of any other alternative. Furthermore, any first-order stochastic dominant alternative should be preferred to all other alternatives for all monotonic utility functions. ${ }^{15}$ Second-order stochastic dominance requires the outcome distribution of the dominant alternative $a$ to be less disperse than the outcome distribution of the dominated alternative $b$. Formally, we state

$$
\forall k: \int_{-\infty}^{k} F_{a}(x) \mathrm{d} x \leq \int_{-\infty}^{k} F_{b}(y) \mathrm{d} y \quad \text { and } \quad \exists k: \int_{-\infty}^{k} F_{a}(x) \mathrm{d} x<\int_{-\infty}^{k} F_{b}(y) \mathrm{d} y,
$$

which implies that the dominant alternative $a$ should be preferred to any dominated alternative $b$ for all concave utility functions. ${ }^{16}$ To state the obvious, absolute dominance implies statewise dominance, statewise dominance implies first-order stochastic dominance which in turn implies second-order stochastic dominance.

\section{Framing}

Individual decision-making behavior is influenced by habits, personal characteristics, and cognitive heuristics of the decision-maker. ${ }^{17}$ Tversky and Kahneman (1981) describe framing as the "decision-maker's conception of the acts, outcomes, and contingencies associated with a particular choice" which, as we will see, can be influenced to systematically induce violations of dominance. ${ }^{18}$ The literature broadly differentiates between consequence-framing and event-framing. Consequence-framing refers to the way outcomes are portrayed, whereas event-framing refers to how the alternatives that determine the outcomes are presented. ${ }^{19}$ As an illustrative example, consider a gain-loss framing experiment from Tversky and Kahneman (1981). ${ }^{20}$ The experiment comprises two subsequent decisions presented together on a single sheet. First, participants choose between a sure gain of $\$ 240$ and a lottery with a $25 \%$ chance to gain $\$ 1000$ and $75 \%$ to gain nothing. Subsequently, participants choose between a sure loss of $\$ 750$ and a lottery with a $75 \%$ to lose $\$ 1000$ and a $25 \%$ chance to lose nothing. As this pair of concurrent decision problems is presented together, it is legitimate to interpret the decision problem as picking a pair out of four possible choice pairs. Interestingly, the most frequently chosen combination, certainty in the first decision and lottery in the second, is dominated by first-order stochastic dominance by

\footnotetext{
15 See Hadar and Russell (1969).

16 See Hadar and Russell (1969).

17 See for example, Putnam and Holmer (1999).

18 This paper includes the famous "Asian Disease Problem".

19 See for example, Birnbaum (2006).

20 See the 3rd and 4th problem in Tversky and Kahneman (1981).
} 
the least frequently chosen combination, lottery in the first and certainty in the second. ${ }^{21}$ This special case of framing takes advantage of a cognitive bias according to which gains and losses are processed differently by decision-makers. ${ }^{22}$ When the prospects are presented in a combined form,

option $1: 25 \%$ chance to win $\$ 240$, and $75 \%$ chance to lose $\$ 760$,

option 2 : $25 \%$ chance to win $\$ 250$, and $75 \%$ chance to lose $\$ 750$,

all individuals are able to detect first-order stochastic dominance. The observed results are not in line with expected utility theory which requires the decision-maker to have a portfolio perspective. ${ }^{23}$ Here, the majority fails to combine the given choices portrayed as a pair of separate decisions. Violations of dominance that occur because of a lack of a portfolio perspective are also called isolation effects.

In a similar study, Tversky and Kahneman (1986) ask participants to choose between two lotteries characterized by the percentage of different colored marbles and the amount of money the participants can win or lose depending on the color of a randomly drawn marble. ${ }^{24}$ The majority (58\%) picks the lottery

$$
\begin{array}{cccc}
90 \% \text { white } & 6 \% \text { red } & 1 \% \text { green } & 3 \% \text { yellow } \\
\text { win } \$ 0 & \text { win } \$ 45 & \text { win } \$ 30 & \text { lose } \$ 15,
\end{array}
$$

which is dominated by first-order stochastic dominance by the lottery

$$
\begin{array}{cccc}
90 \% \text { white } & 7 \% \text { red } & 1 \% \text { blue } & 2 \% \text { yellow } \\
\text { win } \$ 0 & \text { win } \$ 45 & \text { lose } \$ 10 & \text { lose } \$ 15 .
\end{array}
$$

Again, all respondents reject the dominated alternative when the dominance relation is presented transparently. ${ }^{25}$ The technique Tversky and Kahneman (1986) apply to mask the dominating alternatives is to simply combine states that lead to identical outcomes.

Rabin and Weizsäcker (2009) replicate Tversky and Kahneman (1981) in a realstakes laboratory experiment and a survey and find that $28 \%$ of all participants choose dominated alternatives. Higher violation rates are obtained for several hypothetical large-stakes choices. There is no significant effect of education or age on the violation rates. The authors attribute the violations of dominance triggered by framing to narrow-bracketing as defined by Read et al. (1999). Similar to the isolation effect, narrow-bracketing implies that a decision-maker will choose within each choice set according to her preferences but will not take into account that the relevant outcome will be the combined outcome from all of her choices.

Li (2001) conducts several experiments with focus on similarity judgments with lexical and pictorial stimuli that support Kahneman and Tversky's argument on non-

\footnotetext{
${ }^{21}$ Out of 150 participants $73 \%$ chose certainty in decision 1 and lottery in decision 2 and only $3 \%$ chose lottery in decision 1 and certainty in decision 2 .

22 Bosone and Martinez (2017) find that the strength of gain-loss framing for health screening decisions is mediated by the perceived relevance of the issue and the negativity of the consequences.

23 See Markowitz (1952).

24 See problem 8 in Tversky and Kahneman (1986).

25 See problem 7 in Tversky and Kahneman (1986).
} 
transparent dominance, observing a higher rate of violations when problems are presented in an "ill-matched version" which does not allow for direct comparison. ${ }^{26}$ We point out that the effect of framing varies strongly with respect to the audience that is addressed. Wang (1996) shows that the degree of first-order stochastic dominance violation in Kahneman and Tversky's "Asian Disease Problem" depends on the social group context of participating individuals. It turns out that a significantly higher number of people choose the dominated alternative, if the problem is presented in a small group context. The highest violation rates are observed for small family groups. Large anonymous groups show the lowest violation rates.

Birnbaum (1997) provides a recipe for violations of first-order stochastic dominance in multi-branch gambles. Consider the following illustrative gamble:

$$
G_{0}=(\$ 12,0.1 ; \$ 96,0.9),
$$

with a probability of 0.1 to win $\$ 12$ and a probability of 0.9 to win $\$ 96$. Create a slightly better gamble

$$
G_{+}=(\$ 14,0.05 ; \$ 12,0.05 ; \$ 96,0.9)
$$

by splitting the lower branch of $G_{0}(0.1$ to win $\$ 12)$ and a slightly worse gamble

$$
G_{-}=(\$ 12,0.1 ; \$ 90,0.05 ; \$ 96,0.85)
$$

by splitting the higher branch of $G_{-}(0.9$ to win $\$ 96) .{ }^{27} G_{+}$dominates $G_{0}$ which in turn dominates $G_{-} \cdot{ }^{28}$ Using variations of this recipe, Birnbaum and Navarrete (1998) conduct several experiments and find that the majority of participants violate first-order stochastic dominance by choosing $G_{-}$over $G_{+}$. In this study, $70 \%$ choose $G_{-}=(\$ 6,0.05 ; \$ 91,0.03 ; \$ 99,0.92) \quad$ over $\quad G_{+}=(\$ 6,0.02 ; \$ 8,0.03 ; \$ 99,0.95)$. Birnbaum and Bahra (2007) attribute this result and other comparable dominance violations observed in previous literature to coalescing instead of event-framing as described by Tversky and Kahneman (1981). Coalescing is the assumption that probability consequence branches within a gamble yielding to identical outcomes can be combined by adding their probabilities without affecting the utility of the gamble. ${ }^{29}$ The decision-maker should be indifferent between a three-way gamble of winning $\$ 12$ with a probability of $0.1, \$ 12$ with a probability of 0.1 , and $\$ 96$ with a probability of 0.8 and a two-way gamble of winning $\$ 12$ with a probability of 0.2 and $\$ 96$ with a probability of 0.8 . Coalescing is required by almost all modern decision theory frameworks. ${ }^{30}$ By 2006, Birnbaum completed 41 studies with 11,305 participants concluding that violations of stochastic dominance with this

\footnotetext{
${ }^{26}$ Leland (1998) demonstrates that first-order stochastic dominance violations rates are generally insensitive to the statistical dependence or independence of the presented alternatives but sensitive to the way the alternatives are described.

$27 G_{-}=(\$ 12,0.1 ; \$ 90,0.05 ; \$ 96,0.85)$ denotes a gamble in which the outcomes $\$ 12, \$ 90$, and $\$ 96$ occur with probability $10 \%, 5 \%$, and $85 \%$, respectively. Subsequently, all gambles are illustrated in this manner.

28 See Birnbaum and Martin (2003).

29 See Birnbaum (2004a).

30 See Birnbaum (2006).
} 
recipe is a robust finding. ${ }^{31}$ Birnbaum argues that coalescing and event-splitting are powerful tools that can be used to manipulate decision-makers into choosing firstorder stochastic dominated alternatives. Those findings translated into a practical negotiation setting imply that an option can be made more attractive by splitting branches leading to the best outcomes and coalescing those leading to the worst. ${ }^{32}$

Similar to Birnbaum's experiments, Starmer (1999) experiments with 104 subjects requiring them to respond to 20 questions involving binary lotteries. The aim of the study is to test if transitivity is part of human choice behavior. Among the 20 questions are the following three lotteries:

$$
\begin{aligned}
& A=(\$ 14,0.2 ; \$ 0,0.8), \\
& B=(\$ 8,0.3 ; \$ 0,0.7), \\
& C=(\$ 8,0.1 ; \$ 7.75,0.1 ; \$ 0,0.8) .
\end{aligned}
$$

Here, $A$ dominates $B$ and $B$ dominates $C$ by second-order stochastic dominance. Interestingly, one out of four participants experience difficulties in detecting these relations implying non-transitive decision behavior. We note that the level of reported violations is well below violation rates in comparable experimental literature such as Birnbaum (2007) or Levy (2008). In addition to the relatively low level of observed dominance violations, we believe that the origin of the dominance violations in Starmer's experiments is most likely due to coalescing as Starmer uses Birnbaum's recipe described above. Some of the violations may also be due to the relatively high combinatorial complexity of the decision problems.

Wu and Gonzalez (1999) document a violation of first-order stochastic dominance in a setting where the probabilities of events remain unchanged but the outcome of the events differs between the alternatives. ${ }^{33}$ In their first experiment, respondents are asked how much they are willing to pay for two presented alternatives. One alternative, the "packed" alternative, pays the participants $\$ 220$ if baseball team $T_{1}$ or $T_{2}$ wins the World Series and $\$ 0$ if another team wins. The second alternative, the "unpacked" alternative, pays $\$ 220$ to the participants if team $T_{1}$ wins, $\$ 200$ if team $T_{2}$ wins and $\$ 0$ if another team wins the World Series. Although the packed alternative dominates the unpacked alternative by first-order stochastic dominance, participants priced the unpacked alternative significantly higher than the packed alternative. ${ }^{34}$ The authors argue that "the violation demonstrated relies on the robust effect that unpacking an event into constituent components increases the judged probability of that event". 35

\footnotetext{
31 Among others, see Birnbaum and Navarrete (1998), Birnbaum et al. (1999), Birnbaum (1999), Birnbaum and Martin (2003), Birnbaum (2004a, b, 2005b, 2006, 2007, 2008), and for multi-branch games Birnbaum (2005a).

32 See Birnbaum (2007).

$33 \mathrm{Wu}$ and Gonzalez (1999) investigate the multi-attribute concept of cumulative dominance. For the purpose of this paper, we limit our discussion to violations of first-order stochastic dominance.

34 It is proper to speak of first-order stochastic dominance instead of cumulative dominance as we can assign the (unknown) probability $p$ to the outcome "win $\$ 220$ " in the packed alternative and the (unknown) probabilities $p-q$ and $q$ to the outcomes "win $\$ 220$ " and "win $\$ 200$ ", respectively.

35 While the existence of first-order stochastic dominance violations is undoubted, the causes for such violations are less obvious. Levy (2008), for instance, argues that violations of first-order stochastic dominance occur mainly due to the bounded rationality of decision-makers, and thus are an unpredictable phenomenon.
} 
A situation in which a simple change in the presentation of numbers leads to the preference of an absolutely dominated alternative is presented by Yamakishi (1997). In his study, participants rate a disease that kills 1,286 out of 10,000 people as more dangerous than one that kills 24.14 out of 100 people. Yamakishi repeats the study for all leading causes of death and obtains comparable numbers. He interprets his results with the human inability to compare numbers appropriately when being dragged away by either the complexity of the presentation or sensation created by the outcome and concludes by pointing out the importance of communication. The following table provides an overview of all papers discussed in this section.

\begin{tabular}{lll}
\hline References Research question & Type of violation
\end{tabular}

Birnbaum How can violations of the monotonicity principle in decision (1997) theory be explained?

Violations of first-order stochastic dominance

Birnbaum How does the descriptive adequacy of alternative decision(1998) making theories compare to each other?

Violations of first-order stochastic dominance

Birnbaum How do results differ between internet and laboratory

(1999) experiments when testing selected properties of decisionmaking?

Birnbaum In how far can the common consequence paradox of Allais be (2004a) attributed to violations of restricted branch independence and coalescing?

Birnbaum To what extent can manipulations of probability formats, (2004b) branch-splitting, and event-framing lead to paradoxical results that refute rank-dependent utility and cumulative prospect theory?

Birnbaum Compares the predictive accuracy of five descriptive

(2005a) decision-making models using a method for producing stochastic dominance violations that follows Birnbaum (1997)

Birnbaum How do the rank-affected multiplicative weights model, the (2005b) transfer of attention model, and cumulative prospect theory compare with regard to upper/lower distribution independence and restricted branch independence?

Birnbaum Does cumulative prospect theory uphold to tests of (2006) coalescing, stochastic dominance, lower and upper cumulative independence, as well as branch independence?

Birnbaum Compares cumulative prospect theory, the lower gains (2007) decomposition utility model, subjective utility theory and the transfer of attention exchange model with regard to branch-splitting and branch-splitting independence in Allais paradoxes

Birnbaum Is the attention exchange model a better description of human (2008) choice than cumulative prospect theory?

Violations of first-order stochastic dominance

Violations of first-order stochastic dominance

Violations of first-order stochastic dominance

Violations of first-order stochastic dominance

Violations of first-order stochastic dominance

Violations of first-order stochastic dominance

Violations of first-order stochastic dominance

Violations of first-order stochastic dominance 


\begin{tabular}{lc}
\hline References & Research question \\
\hline $\begin{array}{c}\text { Birnbaum and } \\
\text { Bahra (2007) }\end{array}$ & $\begin{array}{c}\text { How do the attention exchange model and cumulative } \\
\text { prospect theory compare when testing for gain-loss } \\
\text { separability and coalescing? }\end{array}$ \\
$\begin{array}{c}\text { Birnbaum and } \\
\text { Martin (2003) }\end{array}$ & $\begin{array}{l}\text { dominance by Birnbaum (1997) generalizable across } \\
\text { people and procedures? }\end{array}$
\end{tabular}

Birnbaum et al. How well does rank-dependent utility theory uphold to (1999)

Bosone and Martinez (2017)

Hadar and Russell (1969)

Leland (1998)

Li (2001)

Putnam and Holmer (1999)

Rabin and Weizsäcker (2009)

Read et al. (1999)

Starmer (1999)

Tversky and Kahneman (1981)

Tversky and Kahneman (1986)

Wang (1996)

Wu and Gonzalez (1999)

Yamakishi (1997) tests of cumulative independence, interval independence, stochastic dominance, and transitivity?

Why is loss-framing more effective than gain-framing in the promotion of health screening?

Discusses properties of first- and second-order stochastic dominance

Does the statistical dependence of alternatives and eventframing influence violations of dominance, independence, and invariance?

How do lexicographical and pictorial stimuli influence similarity judgements?

How does framing and reframing influence negotiations?

Can narrow-bracketing explain violations of first-order stochastic dominance as illustrated in Tversky and Kahneman (1981)?

How does choice bracketing, narrow or broad, influence choices?

Do choices systematically violate transitivity?

How does framing of contingencies and outcomes influence decision-making?

How do various aspects of choice theory interact with each other?

What is the effect of group size and cultural background on decision-making?

What is the influence of event-splitting on violations of dominance in decision theory?

What is the influence of selected stimuli on decisionmaking?
Type of violation

Violations of first-order stochastic dominance

Violations of first-order stochastic dominance

Violations of first-order stochastic dominance

No direct violation of dominance

No experiments

Violations of first-order stochastic dominance

Violations of absolute and stochastic dominance

No experiments

Violations of first-order stochastic dominance

Violations of first-order stochastic dominance

Violations of first-order stochastic dominance

Violations of first-order stochastic dominance

Violations of first-order stochastic dominance

Violations of first-order stochastic dominance

Violations of first-order stochastic dominance

Implicit violations of absolute dominance 


\section{Reference points}

Reference points describe outcome payoffs or outcome probabilities that are being perceived as ex ante neutral. This target return expectation can be regarded as a special form of an aspiration level or in terms of probabilities also as a credible Bayesian prior belief. In line with the psychophysical principle of diminishing sensitivity, reference point effects are strongest close to such reference points and decrease as one moves away. ${ }^{36}$ The effect is well documented and accounted for in modern choice theory frameworks such as Cumulative Prospect Theory. ${ }^{37}$

For illustrative purposes, consider the following experiments by Payne et al. (1980). In the first experiment, participants have to pick a gamble for each of the 6 possible alternative pairs $(A, B),(A, X),(A, Y),(B, X),(B, Y)$, and $(X, Y)$ from the following underlying set of three-outcome gambles,

$$
\begin{aligned}
& A=(\$ 44,0.5 ; \$ 0,0.1 ;-\$ 55,0.4), \\
& B=(\$ 10,0.3 ; \$ 0,0.5 ;-\$ 15,0.2), \\
& X=(\$ 55,0.4 ; \$ 0,0.1 ;-\$ 44,0.5), \\
& Y=(\$ 15,0.2 ; \$ 0,0.5 ;-\$ 10,0.3) .
\end{aligned}
$$

Here, the gambles $B$ and $Y$ dominate $A$ and $X$ by second-order stochastic dominance. In violation of dominance, $37 \%$ of the participants pick $A$ over $B, 37 \% A$ over $Y$, $40 \% X$ over $B$ and $33 \% X$ over $Y^{38}$ In a second experiment,

$$
\begin{aligned}
& A^{+}=(\$ 74,0.5 ; \$ 30,0.1 ;-\$ 25,0.4), A^{-}=(\$ 14,0.5 ;-\$ 30,0.1 ;-\$ 85,0.4), \\
& B^{+}=(\$ 40,0.3 ; \$ 30,0.5 ; \$ 15,0.2), B^{-}=(-\$ 20,0.3 ;-\$ 30,0.5 ;-\$ 45,0.2), \\
& X^{+}=(\$ 85,0.4 ; \$ 30,0.1 ;-\$ 14,0.5), X^{-}=(\$ 25,0.4 ;-\$ 30,0.1 ;-\$ 74,0.5), \\
& Y^{+}=(\$ 45,0.2 ; \$ 30,0.5 ; \$ 20,0.3), Y^{-}=(-\$ 15,0.2 ;-\$ 10,0.5 ;-\$ 40,0.3),
\end{aligned}
$$

which is obtained by adding and subtracting $\$ 30$ to the respective outcomes of the initial gambles

$$
\begin{array}{ll}
17 \% \text { prefer } \mathrm{A}^{+} \text {over } \mathrm{B}^{+}, & 67 \% \text { prefer } \mathrm{A}^{-} \text {over } \mathrm{B}^{-}, \\
17 \% \text { prefer } \mathrm{A}^{+} \text {over } \mathrm{Y}^{+}, & \text {and } \\
23 \% \text { prefer } \mathrm{X}^{+} \text {over } \mathrm{B}^{+}, & 60 \% \text { prefer } \mathrm{A}^{-} \text {over } \mathrm{Y}^{-}, \\
30 \% \text { preferer } \mathrm{X}^{+} \text {over } \mathrm{Y}^{+} \text {over } \mathrm{B}^{-}, & 67 \% \text { prefer } \mathrm{X}^{-} \text {over } \mathrm{Y}^{-} .
\end{array}
$$

Here, the minus gambles $A$ and $X$ have only two outcomes below the reference point zero, whereas $B$ and $Y$ have three negative outcomes. At the same time, the plus gambles $A$ and $X$ have one negative outcome, whereas $B$ and $Y$ have no negative outcomes. In this experiment, the violation rates of second-order stochastic dominance are higher than in the initial experiment and increase for more negative outcomes of the dominating alternatives. Overall, this technique of adding or subtracting constant amounts to choices within pairs of gambles can "trick" individuals

\footnotetext{
36 See for example, Lopes and Oden (1999).

37 See Kahneman and Tversky (1979), Tversky and Kahneman (1981) and Tversky and Kahneman (1992).

38 See experiment 1 in Payne et al. (1980).
} 
into choosing alternatives that are dominated by second-order stochastic dominance. In a follow-up paper, Payne et al. (1981) provide evidence that violations of secondorder stochastic dominance can be avoided if the utility model includes sufficient inflection points. Thus, violations of second-order stochastic dominance crucially depend on the aspiration level concept. Adding structure to this phenomenon, Lopes and Oden (1999) investigate the influence of such salient values within the cumulative prospect theory framework and the security-potential/aspiration theory framework. They conduct two reference point experiments (within-subject and between-subject) designed to cause violations of second-order stochastic dominance. For instance, when comparing choices between a shifted bimodal lottery, with a low-probability median outcome of $\$ 100$, two moderate-probability outcomes of $\$ 50$ and $\$ 150$, and two high-probability outcomes of $\$ 0$ and $\$ 200$, and a peaked lottery, with a high-probability median outcome of $\$ 100$, two moderateprobability outcomes of $\$ 50$ and $\$ 150$, and two low-probability outcomes of $\$ 0$ and $\$ 200$, they find that most decision-makers prefer the shifted bimodal lottery which is dominated by the peaked lottery by second-order stochastic dominance. There are multiple plausible explanations for this behavior. For example, in practice, individuals tend to take extreme risks in times of economic hardship. This applies to managers in troubled firms as well as subsistence workers. Moreover, managers tend to prefer risk-taking for losses. ${ }^{39}$ Lopes and Oden (1999) argue that choices can be governed by non-monotonous preference patterns that depend on whether or not the aspiration level is met with certainty.

Baucells and Heukamp (2006) present a framework to create experimental designs which isolate qualitative features of either the probability weighting function or the value function associated with stochastic dominance conditions in cumulative prospect theory. In some instances, they observe that the majority of people choose second-order stochastic dominated options, possibly by resorting to ad hoc heuristics. The authors refer to Payne (2005) who shows that decisionmakers tend to follow the heuristic of choosing the alternative with the highest probability of strictly positive payoffs. In this context, we note that the presence of a "winning at least something" mentality contributes to the observed results. The following table provides an overview of all papers discussed in this section.

\begin{tabular}{llc}
\hline References & Research question & Type of violation \\
\hline $\begin{array}{l}\text { Baucells and } \\
\begin{array}{l}\text { Heukamp } \\
(2006)\end{array}\end{array}$ & $\begin{array}{c}\text { How can you generalize and extend the second-order } \\
\text { stochastic dominance condition for expected utility to } \\
\text { cumulative prospect theory? }\end{array}$ & $\begin{array}{c}\text { Violations of second- } \\
\text { order stochastic } \\
\text { dominance }\end{array}$ \\
$\begin{array}{c}\text { Kahneman and } \\
\text { Tversky }\end{array}$ & $\begin{array}{c}\text { How to model decisions under uncertainty with the use of } \\
\text { prospect theory? }\end{array}$ & $\begin{array}{c}\text { Violations of first-order } \\
\text { stochastic dominance }\end{array}$ \\
$\begin{array}{c}\text { (1979) } \\
\text { Lopes and Oden } \\
(1999)\end{array}$ & $\begin{array}{c}\text { How does the predictive accuracy of cumulative prospect } \\
\text { theory compare to security-potential aspiration theory }\end{array}$ & $\begin{array}{c}\text { Violations of second- } \\
\text { order stochastic } \\
\text { fominance }\end{array}$ \\
\hline
\end{tabular}

39 See Payne et al. (1980) and Payne et al. (1981). 
Table c continued

\begin{tabular}{|c|c|c|}
\hline References & Research question & Type of violation \\
\hline $\begin{array}{l}\text { Payne et al. } \\
\qquad(1980)\end{array}$ & $\begin{array}{l}\text { How important are reference points for modeling } \\
\text { decisions under uncertainty? }\end{array}$ & $\begin{array}{l}\text { Violations of second- } \\
\text { order stochastic } \\
\text { dominance }\end{array}$ \\
\hline $\begin{array}{l}\text { Payne et al. } \\
\qquad(1981)\end{array}$ & $\begin{array}{l}\text { How important are reference points for modeling } \\
\text { decisions under uncertainty? }\end{array}$ & $\begin{array}{l}\text { Violations of second- } \\
\text { order stochastic } \\
\text { dominance }\end{array}$ \\
\hline Payne (2005) & $\begin{array}{l}\text { What is the importance of overall probabilities of } \\
\text { winning and losing in gambles with more than two } \\
\text { consequences involving gains and losses for decision } \\
\text { theory models? }\end{array}$ & $\begin{array}{l}\text { Violations of first-order } \\
\text { stochastic dominance }\end{array}$ \\
\hline $\begin{array}{l}\text { Tversky and } \\
\text { Kahneman } \\
\text { (1981) }\end{array}$ & $\begin{array}{l}\text { How does framing of contingencies and outcomes } \\
\text { influence decision-making? }\end{array}$ & $\begin{array}{l}\text { Violations of first-order } \\
\text { stochastic dominance }\end{array}$ \\
\hline $\begin{array}{l}\text { Tversky and } \\
\text { Kahneman } \\
\text { (1992) }\end{array}$ & $\begin{array}{l}\text { How to expand upon prospect theory by the use of } \\
\text { cumulative rather than separable decision weights? }\end{array}$ & $\begin{array}{l}\text { Violations of first-order } \\
\text { stochastic dominance }\end{array}$ \\
\hline
\end{tabular}

\section{Certainty effects}

Certainty effects describe phenomena where decision-makers have a tendency to put overproportional decision weights on alternatives with outcomes that are considered certain as compared to outcomes that are perceived merely probable. ${ }^{40}$ Similar to framing and reference points, additional attention is warranted when modeling decision-making subject to certainty effects as certainty can trigger violations of stochastic dominance in various choice settings.

Looking at health related studies, for example, Nielsen (2006) documents that people assign overproportional high value to risk elimination as compared to risk reduction. Bleichrodt and Prades (2009) document a preference reversal in the context of health utility measurement. The observed reversal "can be interpreted as a violation of elementary stochastic dominance, in the sense that if a health state is preferred to death then one of the treatments yields for each state of nature an outcome that is at least as good as the other treatment, but nevertheless, it is less preferred than the dominated treatment" ${ }^{41}$ The authors argue that the anticipation of disappointment and elation when engaging in risky choice as well as the impact of ethical considerations about the value of life are reasons for this behavior. Viscusi et al. (1987) find a similar effect when experimenting with risk-dollar trade-offs for health risks associated with the usage of common consumer products. In their

\footnotetext{
${ }^{40}$ See for example, Kahneman and Tversky (1979) or see Allais (1953) for a well written exposition on various aspects of decision theory including the effect of certainty on decision-making.

${ }^{41}$ See Bleichrodt and Prades (2009).
} 
experiment, subjects are asked to name the extra dollar amount they would be willing to pay for various levels of risk reduction. Participants show diminishing valuation of risk reduction as the extent of risk reduction increases, but when confronted with risk elimination the observed valuation levels are the highest in that study. This can be regarded as a violation of dominance, since higher values are attributed to lower risk reductions whenever risk elimination comes into play. The authors attribute the overproportional valuation of risk elimination as compared to higher levels of risk reduction without total risk elimination to anxiety effects. In other words, anxiety causes overassessment of small probabilities and incredibly high decision weights for risk elimination. The same study also provides evidence of reference effects as increases in risk are valued overproportionally compared to decreases. When participants are asked for the amount of discount they would want to receive for buying the same product with an increased risk to their health, almost all subjects reject to pay any money for the product. When asked to receive money for using the increased risk product, most participants demand huge risk premiums for marginal health risk increases.

Violations of dominance due to certainty effects have also been reported for abstract lotteries in laboratory environments. A good example is Andreoni and Sprenger (2010) who conduct an experiment with uncertainty equivalents. ${ }^{42}$ Respondents exhibit a disproportionate preference for certainty yielding at indirect violations of first-order stochastic dominance. The phenomenon can also be observed for certainty equivalent experiments as conducted by Birnbaum. ${ }^{43}$ The following table provides an overview of all papers discussed in this section.

\begin{tabular}{llc}
\hline References & Research question & Type of violation \\
\hline $\begin{array}{c}\text { Andreoni and } \\
\begin{array}{l}\text { Sprenger } \\
(2010)\end{array}\end{array}$ & $\begin{array}{c}\text { How to utilize uncertainty equivalents to create a direct } \\
\text { test linearity-in-probabilities as implied be the } \\
\text { independence axiom? }\end{array}$ & $\begin{array}{c}\text { Violations of first-order } \\
\text { stochastic dominance }\end{array}$ \\
$\begin{array}{c}\text { Birnbaum } \\
(1992)\end{array}$ & $\begin{array}{c}\text { Can violations of dominance in value judgement } \\
\text { experiments be replicated for experiments with gales? }\end{array}$ & $\begin{array}{c}\text { Violations of first-order } \\
\text { stochastic dominance }\end{array}$ \\
& $\begin{array}{c}\text { Do certainty equivalents in gambles depend on the } \\
\text { distribution of amounts offered for comparison? }\end{array}$ & \\
$\begin{array}{c}\text { Bleichrodt and } \\
\text { Prades (2009) }\end{array}$ & $\begin{array}{c}\text { Are preferences in health utility measurement invariant } \\
\text { to the elicitation method used? }\end{array}$ & $\begin{array}{r}\text { Violations of first-order } \\
\text { stochastic dominance }\end{array}$ \\
$\begin{array}{c}\text { Nielsen (2006) } \\
\text { How to value changes in mortality risk? }\end{array}$ & $\begin{array}{c}\text { Violations of first-order } \\
\text { stochastic dominance }\end{array}$ \\
$\begin{array}{c}\text { Viscusi et al. } \\
\text { (1987) }\end{array}$ & How do various health-risks influence consumer choice & $\begin{array}{c}\text { Violations of first-order } \\
\text { stochastic dominance }\end{array}$ \\
\hline
\end{tabular}

\footnotetext{
${ }^{42}$ Let $(\$ X, p ; \$ Y)$ represent a binary gamble to receive $\$ X$ with probability $p$ and $\$ Y$ otherwise. The uncertainty equivalent to a binary gamble $(\$ X, p ; \$ Y)$ is the probability $q$ such that the decision-maker is indifferent to the gamble $(\$ Y, q ; 0)$.

${ }^{43}$ See e.g., Birnbaum (1992).
} 


\section{Bounded rationality}

A significant amount of empirical and experimental evidence that has been compiled on violations of dominance in decision-making is associated with human limitations, cognitive errors, and computational difficulties. Many of these violations are not in contradiction to normative decision theory since decisionmakers confronted with their "irrational" decision behavior would revise their choice and choose a dominant alternative after sufficient consideration. Such behavior is rather an expression of individuals with rational preferences that make mistakes. $^{44}$

In line with that, Huck and Müller (2012) find that decision-makers with university degrees, high income, and asset holders have significantly lower dominance violation rates based on a survey study that revisits the Allais paradox. Birnbaum (1999) acknowledges the same point and reports that first-order stochastic dominance violation rates in binary gamble experiments decrease with education. Similarly, Levy (2008) documents that more sophisticated and experienced subjects are less likely to violate first-order stochastic dominance. In a consumer portfoliodecision study, Choi et al. (2014) provide significant evidence that violations of stochastic dominance occur more frequently with aged participants, inexperienced participants, participants with lower levels of education, and for decisions with higher levels of complexity. They notice that only a minority of subjects commits violations of first-order stochastic dominance when the violation is transparent, i.e. when the violation is obvious or can easily be detected. Thus, the observed violations may be interpreted as an expression of an interdependent continuum of preferences, individual constraints, and varying levels of decision-making ability, natural to a heterogeneous population.

However, Choi et al. (2007) argue that inconsistencies in individual decisionmaking should not blindly be attributed to error. Even though some individuals in their experiments switch between safe, risky, and intermediate portfolios seemingly at random, overall individual behavior follows a stylized pattern which is in line with kinky preferences and consistent with disappointment aversion. Bone et al. (2009) present three experiments in which the majority of participants appears to be incapable of planning ahead which does not improve with experience. They use a two-stage decision framework with two alternatives in each stage made by either teams or individual decision-makers. The clue is that decision-makers in the first stage do not account for the presence of first-order stochastic dominant alternatives in the second stage, thus choosing an alternative in the first stage results in a path that leads to a dominated outcome in stage two. Bruner (2017) demonstrates that the likelihood of a decision error is decreasing in the level of constant relative risk aversion while investigating the frequency of second-order stochastic dominance violations with risky assets. The observed violation rates are comparably low and appear to be driven by mistakes. In another study, where decision-makers were asked to choose the cheapest network provider among providers with significantly lower prices for within network calls as compared to outside network calls, many

44 See Levy (2008). 
decision-makers failed to account for the size of the network when computing the actual cost of such a phone contract. The vast majority of survey participants preferred a set of nominally lower rates to a set of effectively lower rates. ${ }^{45}$ Decision-makers are particularly prone to mistakes when facing complex tasks under time pressure. Diederich and Busemeyer (1999) document violations of firstorder stochastic dominance with a multidimensional outcome space and under time pressure. Moreover, they confirm that stochastic dominance is violated more frequently than statewise dominance. Note that the observed violation rates are rather low.

In multiple binary gamble experiments, Birnbaum observes violations of dominance when comparing one gamble with two positive outcomes to another with one positive outcome and one zero outcome. ${ }^{46}$ Also, decision-makers asked to perform pricing judgments on gambles with various probabilities of winning, systematically overprice gambles involving a low probability of winning zero. For instance, on average, the gamble $(\$ 0, p ; \$ 96)$ received an overproportionally higher pricing judgment than the gamble $(\$ 24, p ; \$ 96)$ given the probability $p=0.05 .{ }^{47}$ Violations persist for small, large and negative amounts. Violations persist even when participants are given financial incentives. Birnbaum and Thompson (1996) conclude that this phenomenon can be explained as a simple error of judgment that would not occur in a fully transparent direct choice setting. Lowering the number of trials as in Mellers et al. (1992) or allowing participants to choose from a list instead of making judgment calls as in Birnbaum and Sutton (1992), thus reducing complexity, reduces violation rates. In post-experiment interviews, individuals confronted with their choices in violation of dominance, revised their original answer. ${ }^{48}$ Goldstein and Einhorn (1987) report comparable systematic violations of statewise dominance while examining preference reversals. ${ }^{49}$ Statewise dominated bets with one positive and one negative payoff receive a better rating than bets with the same positive payoff as before and a zero payoff. The average rating increases even further when the negative payoffs become more severe. Using a slightly modified experimental approach, Loomes et al. (1989) observe amongst others an indirect violation of statewise dominance. ${ }^{50}$ Given the amount of evidence, doubts remain relative to the general human ability of performing rational judgments in the presence of values that are below individual aspiration levels. Instead of maximizing payoff, some people judge the attractiveness of a given lottery by the probability that the lottery yields an outcome above their aspiration level. So there could be a reference point explanation for this phenomenon.

Shifting the focus from aspiration levels to issues of processing complexity in decision-making, Slovic et al. (2002) ask subjects to rate the attractiveness of a

\footnotetext{
45 See Bommel and Heimel (2005).

46 See Birnbaum et al. (1992), Mellers et al. (1992), Birnbaum and Sutton (1992), Birnbaum (1992), Mellers et al. (1995), Birnbaum and Thompson (1996).

47 See Birnbaum et al. (1992).

48 See Mellers et al. (1995).

49 Experiment 3 in Goldstein and Einhorn (1987).

50 Experiment 2 in Loomes et al. (1989).
} 
gamble on a scale from 0 to 20 . Interestingly, much lower scores are attributed to "win $\$ 9$ with probability 7 / 36" gamble as compared to "win $\$ 9$ with probability 7 / 36 or loose $5 \varnothing$ with probability 29 / 36”. In a follow-up study, Slovic et al. (2004) conclude that mapping figures without being given upper and lower bounds might be a difficult cognitive task to perform. Instead of assessing the decision problem as a whole, a significant number of decision-makers base their attractiveness judgment on the probability of winning. Another study that documents the inability of putting figures in perspective is conducted by Denes-Raj and Epstein (1994). While offering students an opportunity to win $\$ 1$ on every red jelly bean drawn from transparent bowls of jelly bean, they frequently observe students electing to draw from a bowl that contains a greater absolute number, but a smaller proportion of red beans (e.g., 7 in 100), rather than drawing from a bowl with fewer red beans, but better odds (e.g., 1 in 10) of winning. Students confronted with their choice report that although they knew the probabilities were against them, they felt they had a better chance with more red beans in the bowl. Psychologists explain such behavior with the existence of an experimental system that encodes reality in images, metaphors and feelings, and not by rules of logic and evidence. ${ }^{51}$

Insensitivities with respect to variations of low probabilities is a commonly known fact in decision theory. ${ }^{52}$ Those insensitivities are even stronger when affect-rich outcomes such as kisses and electric shocks are introduced. ${ }^{53}$ Such a result is for example obtained by Kunreuther et al. (2001) when asking decision-makers to evaluate the risk of a chemical plant discharge for three very different but low levels of fatality. On average, people assign similar, sometimes even higher, levels of risk to situations with lower levels of fatality. Selten et al. (1999) document overreactions with respect to probability variations while discussing the impact of money used to incentivize participants in experimental decision problem research. Using a binary lottery setting and benchmarked by an increase in the frequency of observed first-order stochastic dominance violations, the authors report greater deviations from risk neutrality for payoffs with binary lottery tickets as compared to direct money payoffs. The discrepancy increases as calculations are simplified and participants are given easy access to expected values and mean variances underlying each alternative. It seems that lottery payoff procedures raise risk awareness and lead to increased risk sensitivity, which in turn leads to increased capriciousness and higher first-order stochastic violation rates. ${ }^{54}$

Finally, we consider situations in which the decision-maker is confronted with revising decisions upon receiving new information. Under the assumption that the human mind follows Bayesian principles, such learning process can be incorporated into new probabilities using Bayesian probability updates. ${ }^{55}$ As an illustrative example, consider the "Game Show" problem. As a contestant in a game show you choose between three doors. Before you make your choice, you are told that there is

\footnotetext{
51 See for example, Slovic et al. (2005).

52 See for example, Sunstein and Zeckhauser (2011).

53 See Rottenstreich and Hsee (2001).

54 For a thorough meta-analysis of the decision theory literature regarding the impact of incentives on experimental research, we refer to Camerer and Hogath (1999).

55 For a comprehensive discussion of the Bayesian probability updates, see e.g., Swinburne (2005).
} 
a prize behind one of the doors. The host then proceeds and opens one empty door and shows you that there is no prize. Finally, you are being asked if you want to revise your choice and pick the other door. Does it make sense to change your prior believe? Under the assumption that the host is not biased towards any of the doors, the host's behavior carries information whether the original choice was correct or not. A simple application of Bayes Theorem shows that switching doors doubles the chances of winning. Interestingly, every time this experiment is conducted in probability classes, there is a significant proportion of students that sticks with their initial choice which is dominated by the alternative of switching, and thereby violate first-order stochastic dominance by ignoring Bayes rule. ${ }^{56}$

We emphasize that judged by the amount of errors encountered in probability updating problems, Bayesian updating appears to be a rather difficult cognitive task for most individuals. It seems that people submit to the complexity of the cognitive task required for dominance detection. Instead of making a rational judgment they show preferences for heuristic solution approaches. In this context, Charness and Levin (2005) find evidence for a "win-stay lose-shift heuristic", i.e., picking alternatives associated with success in the past. In a follow-up study, Charness et al. (2007) show that violations of first-order stochastic dominance occur more frequent in Bayesian probability updating following a failure as compared to following a success in a preceding decision. Thus, participants show an emotional response bias. This trend is reversed when the requirement to perform Bayesian updating is omitted. In all cases, the error rate is higher for participants that are inexperienced with Bayesian updating. Beyond complexity and computational difficulties, experimental papers provide strong evidence that decision-makers tend to ignore prior beliefs or, as shown by Goodie and Fantino (1999), put too much weight on newly received information. When asked to evaluate if a blue or a green cab was involved in a hit-and-run accident at night, most participants choose the blue cab after receiving additional information by a rather unreliable witness who is correct $80 \%$ of the time, even though $85 \%$ of the cabs in the city are Green. Goodie and Fantino (1999) call this a "base rate neglect effect". 57 The following table provides an overview of all papers discussed in this section.

\begin{tabular}{clc}
\hline References & Research question & Type of violation \\
\hline $\begin{array}{c}\text { Birnbaum } \\
(1992)\end{array}$ & $\begin{array}{c}\text { Can violations of dominance in value judgement experiments } \\
\text { be replicated in experiments with gambles? Do certainty } \\
\text { equivalents in gambles depend on the distribution of } \\
\text { amounts offered for comparison? }\end{array}$ & $\begin{array}{c}\text { Violations of first-order } \\
\text { stochastic dominance }\end{array}$ \\
$\begin{array}{c}\text { Birnbaum } \\
(1999)\end{array}$ & $\begin{array}{l}\text { How do results differ between internet and laboratory } \\
\text { experiments when testing selected properties of decision- } \\
\text { making? }\end{array}$ & $\begin{array}{r}\text { Violations of first-order } \\
\text { stochastic dominance }\end{array}$ \\
\hline
\end{tabular}

\footnotetext{
56 In its simplest form the Bayes Theorem states that the conditional probability $\mathbb{P}\left(E_{2} \mid E_{1}\right)$ of event $E_{2}$ occurring, given that event $E_{1}$ has already occurred is given by $\mathbb{P}\left(E_{2} \mid E_{1}\right)=\frac{\mathbb{P}\left(E_{1} \text { and } E_{2}\right)}{\mathbb{P}\left(E_{1}\right)}$.

57 Their study is based on observations of prior research by Tversky and Kahneman (1971), Kahneman and Tversky (1972) and Tversky and Kahneman (1973).
} 


\begin{tabular}{lll}
\hline References & Research question & Type of violation
\end{tabular}

Birnbaum et al. (1992)

Birnbaum and Sutton (1992)

Birnbaum and Thompson (1996)

Bommel and Heimel (2005)

Bone et al. (2009)

Bruner (2017)

Charness and Levin (2005)

Charness et al. (2007)

Choi et al. (2007)

Choi et al. (2014) In how far does rational choice differ among

Denes-Raj and Epstein (1994)

Diederich and Busemeyer (1999)

Goldstein and Einhorn (1987)

Goodie and Fantino (1999)

Huck and Müller (2012)

Kunreuther et al. (2001)

Levy (2008) individuals?

How does the decision-makers point of view influence value judgements?

What are the implications of utility functions implied by configural weight theory and how to measure the utility or subjective value of money?

Under which conditions is monotonicity in decision theory violated?

Are consumers able to choose the most cost efficient mobile contract? In how far is attention carried away by rate comparisons?

Are decision-makers planing ahead in multi-step decision processes?

What is the role of risk-aversion when choosing over risky assets with equivalent expected returns?

How does the "win-stay lose-shift" heuristic interfere with Bayesian updating?

Do decisions of individuals and groups abide to firstorder stochastic dominance when engaging in Bayesian updating?

Present a technique for collecting experimental data on choice under uncertainty using innovative graphical computer interface

When do people behave against their better judgement?

How do decisions differ when outcomes are positively correlated as compared to being negatively correlated?

In how far can expression theory explain violations of dominance in certain binary gambles?

When does base-rate neglect occur under direct experience?

How do responses to the Allais problem differ for different payoffs and across population characteristics?

How do individuals process negative low-probability high-consequence events?

Do individuals systematically violate first-order stochastic dominance as documented by Birnbaum (2004b) or are those results rather due to bounded rationality?
Violations of first-order stochastic dominance

Violations of first-order stochastic dominance

Violations of first-order stochastic dominance

Violations of statewise dominance

Violations of absolute dominance

Violations of secondorder stochastic dominance

Violations of first-order stochastic dominance

Violations of first-order stochastic dominance

Violations of first-order stochastic dominance

Violations of first-order stochastic dominance

Violations of statewise stochastic dominance

Violations of first-order stochastic dominance

Violations of first-order stochastic dominance

Violations of first-order stochastic dominance

Violations of first-order stochastic dominance

Violations of absolute and stochastic dominance

Violations of first-order stochastic dominance 


\begin{tabular}{|c|c|c|}
\hline References & Research question & Type of violation \\
\hline $\begin{array}{l}\text { Loomes et al. } \\
\text { (1989) }\end{array}$ & $\begin{array}{l}\text { To what extent does regret theory in comparison to } \\
\text { information-processing explain preference reversals? }\end{array}$ & $\begin{array}{l}\text { Violations of first-order } \\
\text { stochastic dominance }\end{array}$ \\
\hline $\begin{array}{l}\text { Mellers et al. } \\
\text { (1992) }\end{array}$ & $\begin{array}{l}\text { When do individuals violate dominance in judging } \\
\text { prices for two- and three-outcome gambles? }\end{array}$ & $\begin{array}{l}\text { Violations of first-order } \\
\text { stochastic dominance }\end{array}$ \\
\hline $\begin{array}{l}\text { Rottenstreich } \\
\text { and Hsee } \\
\text { (2001) }\end{array}$ & $\begin{array}{l}\text { Does the S-shaped weighting function in prospect theory } \\
\text { accurately reflect the psychophysics of choice under } \\
\text { uncertainty? }\end{array}$ & $\begin{array}{l}\text { Violations of first-order } \\
\text { stochastic dominance }\end{array}$ \\
\hline $\begin{array}{l}\text { Selten et al. } \\
\text { (1999) }\end{array}$ & $\begin{array}{l}\text { How does framing of contingencies and outcomes } \\
\text { influence decision-making? }\end{array}$ & $\begin{array}{l}\text { Violations of first-order } \\
\text { stochastic dominance }\end{array}$ \\
\hline $\begin{array}{l}\text { Slovic et al. } \\
\quad(2002)\end{array}$ & $\begin{array}{l}\text { When do individuals resort to the affect heuristic in } \\
\text { decision-making? }\end{array}$ & $\begin{array}{l}\text { Violations of first-order } \\
\text { stochastic dominance }\end{array}$ \\
\hline $\begin{array}{l}\text { Slovic et al. } \\
\qquad(2004)\end{array}$ & $\begin{array}{l}\text { How do affect, reason, risk, and rationality interrelate in } \\
\text { decisions under uncertainty? }\end{array}$ & No experiments \\
\hline $\begin{array}{l}\text { Slovic et al. } \\
\qquad(2005)\end{array}$ & $\begin{array}{l}\text { How do fast, instinctive, and intuitive reactions to } \\
\text { danger, so called affect-heuristics, interact with } \\
\text { rational (cost-benefit) risk analysis? }\end{array}$ & No experiments \\
\hline $\begin{array}{l}\text { Sunstein and } \\
\text { Zeckhauser } \\
\text { (2011) }\end{array}$ & $\begin{array}{l}\text { What is the impact of fearsome consequence outcomes } \\
\text { in decision theory? }\end{array}$ & $\begin{array}{l}\text { Violations of first-order } \\
\text { stochastic dominance }\end{array}$ \\
\hline
\end{tabular}

\section{Emotional responses}

The theory of choice has evolved over time uniting insights from various disciplines. This section focuses on the human factor in decision-making, a decision-maker influenced by emotions and other human traits. ${ }^{58}$ For instance, when asked to price life insurance policies for airline traveling, Johnson et al. (1993) observe that decision-makers assign higher values to alternatives that represent probability subsets of other alternatives. In average, life insurance policies that cover terrorism attacks and non-terrorism related mechanical failures were priced significantly higher than life insurance that covers for any cause of death. ${ }^{59}$ The authors infer that the result might be driven by the fact that the media frequently reports terrorism and mechanical failures as sources of danger to travelers. Thus, the observed effect is possibly a result of an availability bias. ${ }^{60}$ An alternative explanation based on Tversky and Kahneman's "Linda experiment" is offered by Wickham (2003). Here, the majority of individuals assigns a higher probability to the conjoint characteristic that Linda is a bank teller and an active feminist as

\footnotetext{
${ }^{58}$ For a discussion of the applicability of insights in psychology to economic theory, see Grether and Plott (1979).

59 This violates the concept of inclusion dominance as the higher priced mechanical failure and terrorism life insurance is a subset of the lower priced life insurance that covers any cause of death.

60 Similar studies where respondents violate inclusion dominance can be found in Fischhoff et al. (1978), Tversky and Kahneman (1983) and Tversky and Koehler (1994).
} 
compared to her just being a bank teller. ${ }^{61} \mathrm{He}$ explains that respondents can get carried away by the initial description of Linda that presents her as a young, single, bright philosophy major who is concerned with issues of discrimination and social justice and participates in anti-nuclear demonstrations. Working as a bank teller does not seem to be a good representation of Linda. Instead, respondents choose the mathematically less probable subset of a feminist bank teller worker.

Next, we discuss the results of two related studies, Abasolo and Tsuchiya (2004) and Abasolo and Tsuchiya (2013), in which Spaniards are asked to choose among health programs involving a trade-off between the overall health level of the population and the distribution of health. People show non-monotonic preferences when health inequalities are regarded as "too large". A majority of respondents prefers a health program that aims at increasing life expectancy for an underprivileged group by 1.5 years rather than having an overall 2 year increase in life expectancy for the whole population. The concern for equality can override the concern for efficiency or people may simply disagree that more is better when accounting for the distribution of those increments. We argue that one option dominates another if it improves on the other option for everybody involved and in all possible states of the world. Engelmann and Strobel (2004) conduct similar experiments in which they study the effects of inequality aversion, efficiency, and max-min preferences. Their experiments involve a hypothetical wealth distribution among three individuals in a game with three possible states. About $30 \%$ of respondents choose pareto-dominated alternatives due to inequality aversion. In all treatments, Engelmann and Strobel (2004) provide evidence for systematic inequality aversion. Interestingly, the concern for equality is higher when the participant is in a high-income position as compared to being in a low income position. Kircher et al. (2009) report that fairness concerns in the presence of social goods cause violations of the independence axiom and the principle of dominance. $^{62}$

Multiple studies analyze the effect of emotions in life or death decision settings. For motivational purposes, consider the money-death trade-off problem by Arrow (1966). One cent is preferred to receiving nothing then, following normative decision theory, there should exist some small probability such that receiving one cent with a small probability of death is preferred to receiving nothing. ${ }^{63}$ Arrow explicates: "This may sound outrageous at first blush, but I think a little reflection will demonstrate the reasonableness of the result." Put into test, the majority of participants in Chanel and Chichilnisky (2013) are not willing to accept a hypothetical gamble involving the decision whether to swallow a pill that may be lethal with probability $\left(10^{-9}\right)$ and receive $\$ 220,000$ upon survival, implying that the value of their life is worth more than $\$ 220,000$ trillion. Thus, fearsome outcomes

\footnotetext{
${ }^{61}$ For the original experiment, we refer to Tversky and Kahneman (1981) and Tversky and Kahneman (1983).

62 For further reading relative to preferences for fairness and equality in decision theory, see Bolton and Ockerfels (2005), Bolton et al. (2000), Karni and Safra (2002) and Karni et al. (2008).

63 More precisely, the example is used to illustrate the implications of the continuity axiom.
} 
influence decision-making and, as we will see in the following, may trigger violations of dominance. ${ }^{64}$

In further lottery experiments with fearsome outcomes by Chanel and Chichilnisky (2009), participants show inabilities to rank alternatives. To exemplify, we cite one of the participants: "I was completely terrified by the last lottery, I first chose $100 \%$, then $0 \%$, then I was not at all sure what I should do." Under conditions of fear, the cortex functionality is hampered by the amygdala leading to ignorance and over-complex processing in the decision-making process. The link to framing is obvious, whether a problem described in a neutral way or masked by emotional terms can be used to influence decision-making. Similarly, Sunstein (2003) and Sunstein and Zeckhauser (2011), survey students about their willingness to pay predefined amounts of money in order to cure cancer using emotional and unemotional descriptions. On average, participants are willing to pay more money for curing fewer people from cancer in the emotional setting that describes cancer as a "very gruesome and intensely painful...[disease that] eats away at the internal organs of the body." In a separate questionnaire, they ask students to evaluate a situation that involves receiving an electric shock today versus receiving the same electric shock in one year from now. We argue that receiving an electric shock in the future dominates the immediate exposure to pain, since future events should be discounted. Contrary to our expectations and not taking into account discounting effects, most students are willing to pay more in order to avoid the electric shock one year from now. The authors explain such behavior with anxiety. More precisely, Sunstein and Zeckhauser (2011) infer that as emotions intensify, they override and take control of rational decision-making. Loewenstein et al. (2001) describe anxiety as a hedonistic burden of itself that induces defensive reactions which do not follow the principles of decision-making theory. Or according to common sense, better a terrible end than an unending terror. On the other hand, what if net present value maximization is not reflective of human preferences per se? Loewenstein and Sicherman (1991) show that the vast majority of respondents prefers an increasing wage profile to a constant or decreasing wage profile although this choice implies less money in terms of net present value and less overall consumption. Even when confronted with this implied dominance violation, respondents disagree and argue that their choice is not in violation of dominance. ${ }^{65}$ The following table provides an overview of all papers discussed in this section.

\begin{tabular}{lll}
\hline References & Research question & Type of violation \\
\hline $\begin{array}{l}\text { Abasolo and } \\
\text { Tsuchiya (2004) }\end{array}$ & $\begin{array}{c}\text { When do distributional issues dominate efficiency } \\
\text { concerns in social healthcare? }\end{array}$ & $\begin{array}{c}\text { Indirect violations of } \\
\text { statewise dominance }\end{array}$ \\
\hline
\end{tabular}

\footnotetext{
${ }^{64}$ Now, the result in Chanel and Chichilnisky (2013) may partially also be due to the certainty effect discussed in Sect. 5. Individuals seem to violate continuity near certain outcomes, see for example Andreoni and Sprenger (2010). The use of fearsome outcomes further influences choice in this instance.

${ }^{65}$ For further interest in variations regarding discounting preferences, see Loewenstein and Thaler (1989) and Loewenstein and Prelec (1993).
} 


\begin{tabular}{|c|c|c|}
\hline References & Research question & Type of violation \\
\hline $\begin{array}{l}\text { Abasolo and } \\
\text { Tsuchiya (2013) }\end{array}$ & $\begin{array}{l}\text { Are the results of Abasolo and Tsuchiya (2004), in } \\
\text { particular the observed violations of dominance, } \\
\text { robust and generalizable? }\end{array}$ & $\begin{array}{l}\text { Indirect violations of } \\
\text { statewise dominance }\end{array}$ \\
\hline $\begin{array}{l}\text { Chanel and } \\
\text { Chichilnisky } \\
\text { (2009) }\end{array}$ & $\begin{array}{l}\text { How do conditions of fear and catastrophic outcomes } \\
\text { influence decision-making? }\end{array}$ & $\begin{array}{l}\text { Violations of first-order } \\
\text { stochastic dominance }\end{array}$ \\
\hline $\begin{array}{l}\text { Chanel and } \\
\text { Chichilnisky } \\
\text { (2013) }\end{array}$ & $\begin{array}{l}\text { How should extreme events and extreme responses be } \\
\text { incorporated in decision theory? }\end{array}$ & $\begin{array}{l}\text { Violations of first-order } \\
\text { stochastic dominance }\end{array}$ \\
\hline $\begin{array}{l}\text { Engelmann and } \\
\text { Strobel (2004) }\end{array}$ & $\begin{array}{l}\text { How do efficiency concerns, maximin preferences, and } \\
\text { inequality aversion interact in decision-making? }\end{array}$ & $\begin{array}{l}\text { Violations of first-order } \\
\text { stochastic dominance }\end{array}$ \\
\hline $\begin{array}{l}\text { Johnson et al. } \\
\text { (1993) }\end{array}$ & $\begin{array}{l}\text { How can decision framing be used to influence } \\
\text { insurance purchase decisions? }\end{array}$ & $\begin{array}{l}\text { No direct violation of } \\
\text { dominance }\end{array}$ \\
\hline $\begin{array}{l}\text { Kircher et al. } \\
\quad(2009)\end{array}$ & $\begin{array}{l}\text { How can the concept of fairness be incorporated into } \\
\text { utility based decision theory? }\end{array}$ & $\begin{array}{l}\text { Violations of first-order } \\
\text { stochastic dominance }\end{array}$ \\
\hline $\begin{array}{l}\text { Loewenstein and } \\
\text { Sicherman } \\
\text { (1991) }\end{array}$ & $\begin{array}{l}\text { Why do workers prefer increasing over decreasing wage } \\
\text { profiles? }\end{array}$ & $\begin{array}{l}\text { Violations of statewise } \\
\text { dominance }\end{array}$ \\
\hline $\begin{array}{l}\text { Loewenstein et al. } \\
\qquad(2001)\end{array}$ & $\begin{array}{l}\text { How can feelings and emotions be incorporated into } \\
\text { decision theory under uncertainty? }\end{array}$ & No experiments \\
\hline Sunstein (2003) & $\begin{array}{l}\text { Under what emotional circumstances do individuals } \\
\text { neglect probabilities and instead focus on the badness } \\
\text { of the outcome? }\end{array}$ & $\begin{array}{l}\text { Violations of first-order } \\
\text { stochastic dominance }\end{array}$ \\
\hline $\begin{array}{l}\text { Sunstein and } \\
\text { Zeckhauser } \\
\text { (2011) }\end{array}$ & How does fear influence individual decision-making? & $\begin{array}{l}\text { Violations of first-order } \\
\text { stochastic dominance }\end{array}$ \\
\hline $\begin{array}{l}\text { Tversky and } \\
\text { Kahneman } \\
\text { (1981) }\end{array}$ & $\begin{array}{l}\text { How does framing of contingencies and outcomes } \\
\text { influence decision-making? }\end{array}$ & $\begin{array}{l}\text { Violations of first-order } \\
\text { stochastic dominance }\end{array}$ \\
\hline $\begin{array}{l}\text { Tversky and } \\
\text { Kahneman } \\
\text { (1983) }\end{array}$ & $\begin{array}{l}\text { When do the representativeness heuristic and the } \\
\text { availability heuristic make a conjunction appear more } \\
\text { probable than one of its constituents? }\end{array}$ & $\begin{array}{l}\text { Violations of statewise } \\
\text { dominance }\end{array}$ \\
\hline Wickham (2003) & $\begin{array}{l}\text { How does the representativeness heuristic influence } \\
\text { judgements involving entrepreneurial success and } \\
\text { failure? }\end{array}$ & $\begin{array}{l}\text { Violations of statewise } \\
\text { dominance }\end{array}$ \\
\hline
\end{tabular}

\section{Less-is-better and peak-end rule}

In this section, we want to discuss situations in which people prefer less of a good thing to more of the same and are even willing to pay more for less. Such behavior may not always imply an immediate dominance violation as defined in the introduction, but can be categorized as paradoxes of choice, in the sense that individual preferences may not be stable or well defined.

In a field experiment with sports card memorabilia, List (2002) offers two different bundles of baseball cards to professional dealers and ordinary consumers. One of the bundles, the smaller one, contains 10 highly valuable cards and has a book value of around $\$ 15$. The other bundle, the bigger one, contains all 10 cards 
from the smaller bundle and additionally 3 different baseball cards that are graded as "poor". The book value of the latter bundle is around $\$ 18$. One would expect from a rational decision-maker to be willing to pay more for the 13-card bundle than for the 10-card bundle, but instead List's experiment documents a preference reversal. Albeit, the 13-card bundle is valued higher than the 10-card bundle when offering the two bundles juxtaposed, the results reverse when the bundles are auctioned separately and isolated from each other. Obviously, the smaller bundle is objectively inferior to the bigger bundle (with respect to the book value as well as with respect to the number of cards). Thus, the higher rating for the 10-card bundle in the auction setting seems irrational. As the two alternatives are auctioned separately, the higher valuation of the low-value option is not a dominance violation in the strict sense: The 13-card bundle dominates the 10-card bundle only in the omniscient view of the experimenter. The decision-makers do not know about the existence of the other card bundle when they are asked to rate the presented card bundles in the auction. Thus, they do not really "prefer" one alternative over the other. A similar decision pattern is documented by Hsee (1998) who conducts four studies in which a more valuable option receives a lower rating than a comparably less valuable option if the options are presented separately and therewith evaluated separately by the participants of the experiment. In experiments by Leszcyc et al. (2008), participants are willing to pay a higher price for a single good than for a bundle consisting of the same good and an additional useful, wanted and undamaged good. To obtain this result, the additional item needs to be low in value with reasonable certainty, whereas the other item's value should be uncertain. ${ }^{66}$ The underlying effect is called "less-is-better" effect. There exists a significant amount of publications that present empirical studies and discuss the "less-is-better" effect. ${ }^{67}$ Explanations as to why the "less-is-better" effect arises are discussed actively, for instance, the want/should proposition (Bazerman et al. 1998), the evaluability hypothesis (Bazerman et al. 1992; Hsee 1996), and the norm theory (Kahneman and Miller 1986).

The second psychological phenomenon that we want to discuss in this section is the so called "peak-end" rule. Findings related to the "peak-end" rule are not a result of the isolated presentation of the alternatives, but more related to the fact that when evaluating experiences or events, people pay more attention to the peak and the end of the event or experience. Participants that exhibit such behavior have difficulties creating consistent preference orders. Kahneman et al. (1993) find that individuals prefer a minute of $14{ }^{\circ} \mathrm{C}$ water in a cold presser followed by another thirty seconds of $15^{\circ} \mathrm{C}$ water to a minute of $14^{\circ} \mathrm{C}$ alone. So the more harmful alternative is preferred over the less harmful. This result can be explained by normative decision theory to the extent that individuals choose the alternative which feels more comfortable when asked which of the baths they would want to

\footnotetext{
66 Note that these results are again obtained by a separate presentation of the alternatives to the participants of this auction setting.

67 See for example, Bazerman et al. (1992) or Blount and Bazerman (1996). Bazerman et al. (1999) review this literature.
} 
take one more time. ${ }^{68}$ The "peak-end" rule cannot only be observed in experiments about experiences but also in valuation of future events. Diener et al. (2001) for example, find that participants rate a wonderful life with an abrupt end higher than a life with additional mildly pleasant years. Another study is presented by Varey and Kahneman (1992) in which individuals value a painful experience as more bearable than a less painful experience. They do not refer to the "peak-end" rule in their reasoning but to reference points, i.e., "the more general hypothesis that outcomes are evaluated with respect to a reference level and that losses loom larger gains". ${ }^{69}$ The following table provides an overview of all papers discussed in this section.

\begin{tabular}{|c|c|c|}
\hline References & Research question & Type of violation \\
\hline $\begin{array}{l}\text { Diener et al. } \\
\quad(2001)\end{array}$ & $\begin{array}{l}\text { Why does almost any utility concept unavoidably imply } \\
\text { a violation rationality, in particular transitivity and } \\
\text { stochastic dominance? }\end{array}$ & No experiments \\
\hline Do et al. (2008) & $\begin{array}{l}\text { How do pleasurable experiences influence decision- } \\
\text { making? }\end{array}$ & $\begin{array}{l}\text { No direct violation of } \\
\text { dominance }\end{array}$ \\
\hline Hsee (1998) & $\begin{array}{l}\text { Under what circumstances are low-value options rated } \\
\text { higher than other more valuable options? }\end{array}$ & $\begin{array}{l}\text { No direct violation of } \\
\text { dominance }\end{array}$ \\
\hline $\begin{array}{l}\text { Leszcyc et al. } \\
\qquad(2008)\end{array}$ & $\begin{array}{l}\text { How can the hyper-subadditivity in bundle valuation be } \\
\text { explained }\end{array}$ & $\begin{array}{l}\text { No direct violation of } \\
\text { dominance }\end{array}$ \\
\hline List (2002) & $\begin{array}{l}\text { When do individuals place higher bids for low-value } \\
\text { options than for high-value options in auctions? }\end{array}$ & $\begin{array}{l}\text { No direct violation of } \\
\text { dominance }\end{array}$ \\
\hline $\begin{array}{l}\text { Kahneman et al. } \\
\text { (1993) }\end{array}$ & $\begin{array}{l}\text { When do individuals prefer a longer duration of } \\
\text { discomfort compared to a shorter duration } \\
\text { discomfort? }\end{array}$ & $\begin{array}{l}\text { Violations of absolute } \\
\text { dominance }\end{array}$ \\
\hline $\begin{array}{l}\text { Redelmeier and } \\
\text { Kahneman } \\
\text { (1996) }\end{array}$ & $\begin{array}{l}\text { How do patients retrospectively evaluate painful } \\
\text { medical procedures? }\end{array}$ & $\begin{array}{l}\text { No direct violation of } \\
\text { dominance }\end{array}$ \\
\hline $\begin{array}{l}\text { Schreiber and } \\
\text { Kahneman } \\
\text { (2000) }\end{array}$ & $\begin{array}{l}\text { How do individuals evaluate unpleasant sounds in } \\
\text { retrospect? }\end{array}$ & $\begin{array}{l}\text { No direct violation of } \\
\text { dominance }\end{array}$ \\
\hline $\begin{array}{l}\text { Varey and } \\
\text { Kahneman } \\
\text { (1992) }\end{array}$ & $\begin{array}{l}\text { How do individuals evaluate aversive experiences of } \\
\text { varying durations in retrospect? }\end{array}$ & $\begin{array}{l}\text { No direct violation of } \\
\text { dominance }\end{array}$ \\
\hline
\end{tabular}

\section{Concluding remarks}

In this paper, we reviewed empirical, experimental and theoretical contributions for violations of dominance and categorized our findings according to their most common causes, namely framing, reference points, certainty effects, bounded

\footnotetext{
${ }^{68}$ Similar results can be found in Redelmeier and Kahneman (1996), Schreiber and Kahneman (2000), Do et al. (2008).

${ }^{69}$ See Kahneman and Tversky (1979).
} 
rationality, emotional responses, the "less-is-more" effect, and the "peak-end" rule. The observed violations of dominance indicate that a systematic, complete, and transitive preference ordering over all relevant alternatives as required by the normative theory of choice, is not always possible. The individual level of awareness, perception, and cognitive capacity of each involved decision-maker may not always suffice to detect and pick a dominant alternative over its dominated alternatives. Adding a further layer of complexity to decision-making are emotional responses, since decision-makers exposed to a state of enthusiasm, a state of joy or put under the influence of fear and anxiety, disregard or exclude given dominant alternatives from the set of feasible alternatives.

Overall, most studies document violations of stochastic dominance. This is not surprising since recent literature focuses on decisions under uncertainty. Moreover, some concepts of stochastic dominance such as second-order stochastic dominance may not be sufficiently intuitive to decision-makers, and are thus violated more frequently. We find that a significant amount of dominance violations are related to bounded rationality, random errors, and limits to individual information processing abilities. The observed anomalies may be interpreted as an expression of an interdependent continuum of preferences, individual constraints, and varying levels of decision-making ability. At the same time, in some instances, even after thorough discussion of all choice implications, not all individuals participating in the reviewed studies were willing to choose an alternative in accordance with the dominance principle. This was either preference-driven for example by inequality or disappointment aversion, or due to the human nature of the decision-maker which is influenced by emotions. With respect to methodology, the vast majority of studies investigating violations of dominance relies on controlled laboratory experiments followed by surveys. Studies that detect violations of dominance outside of a controlled laboratory environment are scarce.

Acknowledgements We thank Thomas Pfeiffer, Katherine Tiede, Rudolf Vetschera, the S.I. Rationality of Decisions in Business Research Guest Editors, Alexander Dilger and Marko Sarstedt, and two anonymous referees for their valuable comments and suggestions. Funding from the Austrian Science Fund (FWF) under Grant W1229 is gratefully acknowledged.

Open Access This article is distributed under the terms of the Creative Commons Attribution 4.0 International License (http://creativecommons.org/licenses/by/4.0/), which permits unrestricted use, distribution, and reproduction in any medium, provided you give appropriate credit to the original author(s) and the source, provide a link to the Creative Commons license, and indicate if changes were made.

\section{References}

Abasolo, Ignacio, and Aki Tsuchiya. 2004. Exploring Social Welfare Functions and Violation of Monotonicity: An Example from Inequalities in Health. Journal of Health Economics 23: 313-329.

Abasolo, Ignacio, and Aki Tsuchiya. 2013. Is More Health Always Better for Society? Exploring Public Preferences that Violate Monotonicity. Theory and Decision 74 (4): 539-563.

Allais, Maurice. 1953. Le comportement de l'homme rationnel devant le risque: critique des postulats et axiomes de l'école américaine. Econometrica 21: 503-546. 
Amiel, Yoram, and Frank Cowell. 1993. Monotonicity, dominance and the pareto principle. Economics Letters 45 (4): 447-450.

Andreoni, James, and Sprenger, Charles. 2010. Uncertainty equivalents: Linear tests of the independence axiom. Unpublished manuscript retrieved from http://www.nber.org/papers/w17342.pdf. Accessed 10 Oct 2017

Arrow, Kenneth J. 1966. The Theory of Choice Under Uncertainty. Synthese 16: 253-269.

Baucells, Mane, and Franz H. Heukamp. 2006. Stochastic Dominance and Cumulative Prospect Theory. Management Science 52 (9): 1409-1423.

Bawa, Vijany S. 1982. Stochastic Dominance: A Research Bibliography. Management Science 28: 698-712.

Bazerman, Max H., George F. Loewenstein, and Sally Blount White. 1992. Reversals of Preference in Allocation Decisions: Judging an Alternative versus Choosing among Alternatives. Administrative Science Quarterly 37: 220-240.

Bazerman, Max H., Ann E. Tenbrunsel, and Kimberly Wade-Benzoni. 1998. Negotiating with Yourself and Losing: Making Decisions with Competing Internal Preferences. The Academy of Management Review 23: 225-241.

Bazerman, Max H., Don A. Moore, Ann E. Tenbrunsel, Kimberly Wade-Benzoni, and Sally Blount. 1999. Explaining how preferences change across joint versus separate evaluation. Journal of Economic Behavior and Organization 39: 41-58.

Birnbaum, Michael H., and Martin, T. 2003. Generalization across people, procedures, and predictions: Violations of stochastic dominance and coalescing. In Emerging perspectives on decision research, ed. S. L. Schneider \& J. Shanteau, pp. 84-107. New York: Cambridge University Press.

Birnbaum, Michael H. 1992. Violations of Monotonicity and Contextual Effects in Choice-Based Certainty Equivalents. Psychological Science 3: 310-314.

Birnbaum, Michael H. 1997. Choice, decision, and measurement: Essays in honor of R. Duncan Luce Chap. Violations of monotonicity in judgement and decision making, 73-100. Mahwah: Erlbaum.

Birnbaum, Michael H. 1998. Decision Research from Baysian approaches to mormative systems: Reflections on the contributions honor of Ward Edwards. In Chapter The Paradoxes of Allais, Stochastic Dominance, and Decision Weights, ed. J.C. Chanteau, B.A. Mellers, and D. Schum, 1-20. Norwell: Kluwer Academic.

Birnbaum, Michael H. 1999. Testing Critical Pproperties of Decision Making On the Internet. Psychological Science 10: 399-407.

Birnbaum, Michael H. 2001. International Encyclopedia of the Social and Behavioral Science. In International Encyclopedia of the Social and Behavioral Science. Chap. Decision and Choice: Paradoxes of Choice, ed. N.J. Smelser, and P.B. Baltes, 1-14. Oxford: Elsevier.

Birnbaum, Michael H. 2004a. Causes of Allais common consequence paradoxes: An experimental dissection. Journal of Mathematical Psychology 48: 87-106.

Birnbaum, Michael H. 2004b. Tests of Rank-Dependent Utility and Cumulative Prospect Theory in Gambles Represented by Natural Frequencies: Effects of Format, Event Framing, and Branch Splitting. Organizational Behavior and Human Decision Processes 95 (1): 40-65.

Birnbaum, Michael H. 2005a. A comparison of Five Models that Predict Violations of First-Oder Stochastic Dominance in Risky Decision Making. The Journal of Risk and Uncertainty 31: 263-287.

Birnbaum, Michael H. 2005b. Three New Tests of Independence That Differentiate Models of Risky Decision Making. Management Science 51: 1346-1358.

Birnbaum, Michael H. 2006. Evidence against prospect theories in gambles with positive, negative, and mixed consequences. Journal of Economic Psychology 27: 737-761.

Birnbaum, Michael H. 2007. Tests of branch splitting and branch-splitting independence in Allais paradoxes with positive and mixed consequences. Organizational Behaviour and Human Decision Process 102: 154-173.

Birnbaum, Michael H. 2008. New Paradoxes of Risky decision Making. Psychological Review 115: 463-501.

Birnbaum, Michael H., and Jeffrey P. Bahra. 2007. Gain-Loss Separability and Coalescing in Risky Decision Making. Management Science 153: 1016-1028.

Birnbaum, Michael H., and Juan b Navarrete. 1998. Testing Descriptive Utility Theories: Violations of Stchoastic dominance and Cumulative Independence. Journal of Risk and Uncertainty 17: 49-78.

Birnbaum, Michael H., and Sara E. Sutton. 1992. Scale Convergence and Utility Measurement. Organizational Behavior and Human Decision Processes 52: 183-215. 
Birnbaum, Michael H., and Laura A. Thompson. 1996. Violations of Monotonicity in choices between gambles and Certain Cash. The American Journal of Psychology 109: 501-523.

Birnbaum, Michael H., Gregory Coffey, Barbara A. Mellers, and Robin Weiss. 1992. Utility Measurement: configural-Weigth theory and the Judge's Point of View. Journal of Experimental Psychology 18: 331-346.

Birnbaum, Michael H., Jamie N. Patton, and Melissa K. Lott. 1999. Evidence against Rank-Dependet Utility Theories: Tests of cumulative Independence, Interval Independence, Stochastic Dominance, and Transitivity. Organizational Behavior and Human Decision Processes 77: 44-83.

Bleichrodt, Han, and Jose Luis Pinto Prades. 2009. New evidence of preference reversals in health utility measurement. Health Economics 18: 713-726.

Blount, S., and M.H. Bazerman. 1996. The Inconsistent Evaluation of Comparative Payoffs in Labor Supply and Bargaining. Journal of Economic Behaviour and Organization 30: 1-14.

Bolton, G., and A. Ockerfels. 2005. ERC A Theory of equity, Reciprocity and Competition. American Economic Review 90: 166-193.

Bolton, G., J. Brandts, and A. Ockerfels. 2000. Fair procedures: Evidence from games involving lotteries. The Economic Journal 115: 1054-1076.

Bommel, Friedel, and Jana Heimel. 2005. A fallacy of dominannt price vectors in network industries. Review of Network Economics 4 (3): 197-204.

Bone, John, John D. Hey, and John Suckling. 2009. Do people plan? Experimental Economics 12: 12-25.

Bosone, Lucia, and Frederic Martinez. 2017. When, how and why is loss-framing more effeffect than gain- and non-gain-framing in the promotion of detection behaviors. International Review of Social Psychology 30 (1): 184-192.

Bruner, David M. 2017. Does decision error decrease with risk aversion. Experimental Economics 20: 259-273.

Camerer, Colin F., and Robin M. Hogath. 1999. The Effects of Financial Incentives in Experiments: A Review and Capital-Labor-Production Framework. Journal of Risk and Uncertainty 19: 7-42.

Chanel, Olivier, and Graciela Chichilnisky. 2009. The influence of fear in decisions: Experimental evidence. Journal of Risk and Uncertainty 39: 271-298.

Chanel, Olivier, and Graciela Chichilnisky. 2013. Valuing life: experimental evidence using sensitivity to rare events. Ecological Economics 85: 198-205.

Charness, Gary, and Dan Levin. 2005. When Optimal Choices Feel Wrong: A Laboratory Study of Bayesian Updating, Complexity, and Affect. The American Economic Review 95 (4): 1300-1309.

Charness, Gary B., Edi Karni, and Dan Levin. 2007. Individual and Group Decision Making Under Risk: An Experimental Study of Bayesian Updating and Violations of First-order Stochastic Dominance. Journal of Risk and Uncertainty 35 (2): 129-148.

Choi, Syngjoo, Raymond Fisman, Douglas Gale, and Shachar Kariv. 2007. Consistency and Heterogeneity of Individual Behavior under Uncertainty. American Economic Review 97: 1921-1938.

Choi, Syngjoo, Shachar Kariv, Wieland Müller, and Dan Silverman. 2014. Who is (More) Rational? American Economic Review 104 (6): 1518-1550.

Covello, Vincent T., and Jeryl Mumpower. 1985. Risk Analysis and Risk Management: An Historical Perspective. Risk Analysis 5 (2): 103-120.

Denes-Raj, Veronika, and Seymour Epstein. 1994. Conflict Between Intuitive and Rational Processing: When People Behave Against Their Better Judgment. Journal of Personality and Social Psychology 66 (5): 819-829.

Diederich, Adele, and Jerome R. Busemeyer. 1999. Conflict and the Stochastic-Dominance Principle of Decision Making. Psychological Science 10 (4): 353-359.

Diener, Ed, Derrick Wirtz, and Shigehiro Oishi. 2001. End Effects of Rated Life Quality: The James Dean Effect. Psychological Science 12: 124-128.

Do, Amy M., Alexander V. Rupert, and George Wolford. 2008. Evaluations of pleasurable experiences: the peak-end rule. Psychonomic Bulletin and Review 15: 96-98.

Engelmann, Dirk, and Martin Strobel. 2004. Inequality Aversion, Effciency, and Maximin Preferences in Simple Distribution Experiments. The American Economic Review 94 (4): 857-869.

Fischhoff, Baruch, Paul Slovic, and Sarah Lichtenstein. 1978. Fault trees: Sensitivity of estimated failure probabilities to problem representation. Journal of Experimental Psychology 4: 330-334.

Goldstein, William M., and Hillel J. Einhorn. 1987. Expression Theory and the Preference Reversal Phenomena. Psychological Review 94 (2): 236-254. 
Goodie, A.S., and E. Fantino. 1999. What Does and Does Not Alleviate Base-Rate Neglect Under Direct Experience. The Journal of Behavioral Decision Making 12 (4): 307-335.

Grether, David M., and Charles R. Plott. 1979. Econnomic Theory of Chooice and the Preference Reversal Phenomenon. The American Economic Review 69: 623-638.

Hadar, Josef, and William R. Russell. 1969. Rules for Ordering Uncertain Prospects. The American Economic Review 59: 25-34.

Hsee, Christopher K. 1996. The Evaluability Hypothesis: An Explanation for Preference Reversals between Joint and Separate Evaluations of Alternatives. Organizational Behaviour and Human Decision Processes 67: 247-257.

Hsee, Christopher K. 1998. Less Is Better: When Low-value Options Are Valued More Highly than Highvalue Options. Journal of Behavioral Decision Making 11: 107-121.

Huck, Steffen, and Wieland Müller. 2012. Allais for All: Revisiting the Paradox in a Large Representative Sample. Journal of Risk and Uncertainty 44 (3): 261-293.

Johnson, Eric J., John Hershey, Jacqueline Meszaros, and Howard Kunreuther. 1993. Framing, Probability Distortions, and Insurance Decisions. Journal of Risk and Uncertainty 7: 35-51.

Kahneman, Daniel, and Dale T. Miller. 1986. Norm Theory: Comparing Reality to Its Alternatives. Psychological Review 93: 136-153.

Kahneman, Daniel, and Amos Tversky. 1972. Subjective Probability: A judgement of Representativeness. Cognitive Psychology 3 (3): 430-454.

Kahneman, Daniel, and Amos Tversky. 1979. Prospect Theory: An Analysis of Decision under Risk. Econometrica 47: 263-292.

Kahneman, Daniel, and Amos Tversky. 1986. Rational Choice and the Framing of Decisions. The Journal of Business 59: 151-278.

Kahneman, Daniel, Barbara L. Fredrickson, Charles A. Schreiber, and Donald A. Redelmeier. 1993. When More Pain is Preferred to Less: Adding a Better End. Psychological Science 4 (6): 401-405.

Karni, Edi, and Zvi Safra. 2002. Individual Sense of Justice: A Utility Representation. Econometrica 70 (1): 263-284.

Karni, Edi, Tim Salmon, and Barry Sopher. 2008. Individual Sense of Fairness: An Experimental Study. Experimental Economics 11 (2): 174-189.

Keys, Daniel J., and Barry Schwartz. 2007. Leaky Rationality - How Research on Behavioral Decision Making Challenges Normative Standards of Rationality. Perspectives on Psychological Science 2: $162-180$.

Kircher, Philipp, Sandroni, Alvaro, Ludwig, Sandra. 2009. Fairness: A Critique to the Utilitarian Approach. In SFB/TR 15 Discussion Paper No. 288.

Kunreuther, Howard, Nathan Novemsky, and Daniel Kahneman. 2001. Making Low Probabilities Useful. Journal of Risk and Uncertainty 23 (2): 103-120.

Laux, Helmut, Robert M. Gillenkirch, and Heike Y. Schnek-Mathes. 2014. Entscheidungstheorie, 9th ed. Berlin: Springer.

Leland, Jonathan W. 1998. Similarity Judgments in choice Under Uncertainty: A Reinterpretation of the Predictions of Regret Theory. Managment Science 44: 659-672.

Leszcyc, Popkowski, T.L. Peter, John W. Pracejus, and Yingtao Shen. 2008. Why more can be less: An inference-based explanation for hyper-subadditivity in bundle valuation. Organizational Behavior and Human Decision Processes 105 (2): 233-246.

Levy, Haim. 1992. Stochastic dominance and Expected Utility: Survey and Analysis. Management Science 38: 555-593.

Levy, Haim. 2008. First degree stochastic dominance violations: Decision weights and bounded rationality. The Economic Journal 118: 759-774.

Levy, Moshe, and Haim Levy. 2002. Prospect Theory: Much Ado About Nothing? Management Science 48: 1334-1349.

Li, Shu. 2001. Extended Research on Dominance Violations in Similarity Judgments: The equate-todifferentiate interpretation. The Korean Journal of Thinking and Problem Solving 11: 13-38.

Li, Shengwu. 2017. Obviously strategy-proof mechanisms. American Economic Review 107 (11): 3257-3287.

List, John A. 2002. Preference Reversals of a Different Kind: The "More Is Less" Phenomeno. The American Economic Review 92: 1636-1643.

Loewenstein, George, and Drazen Prelec. 1993. Preferences for Sequences of Outcomes. Psychological Review 100: 91-108. 
Loewenstein, George, and Nachum Sicherman. 1991. Do Workers Prefer Increasing Wage Profiles? Journal of Labor Economics 9: 67-84.

Loewenstein, George, and Richard H. Thaler. 1989. Anomalies: Intertemporal Choice. The Journal of Economic Perspectives 3: 181-193.

Loewenstein, George F., Elke U. Weber, Christopher K. Hsee, and Ned Welch. 2001. Risk and Feelings. Psycological. Bulletin 127: 267-286.

Loomes, Graham, Chris Starmer, and Robert Sugden. 1989. Preference reversal: Information-processing effect or rational non-transitive choice? The Economic Journal 99: 140-151.

Lopes, Lola L., and Gregg C. Oden. 1999. The Role of Aspiration Level in Risky Choice: A Comparison of Cumulative Prospect Theory and SP/A Theory. Journal of Mathematical Psychology 43: 286-313.

Luce, R.Duncan, and Detlof von Winterfeldt. 1994. What Common Ground Exists for Descriptive, Prescriptive, and Normative Utility Theories? Management Science 40 (2): 263-279.

Markowitz, Harry. 1952. Portfolio Selection. The Journal of Finance 7: 77-91.

Mellers, Barbara, Robin Weiss, and Michael Birnbaum. 1992. Violations of Dominance in Pricing Judgement. Journal of Risk and Uncertainty 5: 73-90.

Mellers, Barbara A., Pratricia M. Berretty, and Michael H. Birnbaum. 1995. Dominance Violations in Judged Prices of Two- and Three-outcome Gambles. Journal of Behavioral Decision Making 8: 201-216.

Nielsen, Jytte S. 2006. Valuing changes in mortality risk. Health Economics Papers, pp. 1-137.

Payne, John W. 2005. It is Whether You Win or Lose: The Importance of the Overall Probabilities of Winning or Losing in Risky Choice. The Journal of Risk and Uncertainty 30 (1): 5-19.

Payne, John W., Dan J. Laughhunn, and Roy Crum. 1980. Translation of Gambles and Aspiration Level Effects in Risky Choice Behavior. Management Science 26 (19): 1039-1060.

Payne, John W., Dan J. Laughhunn, and Roy Crum. 1981. Further Tests of Aspiration Level Effects in Risky Choice Behavior. Management Science 27 (8): 953-958.

Putnam, Linda L., and Holmer, Majia. 1992. Framing, Reframing, and Issue Development. In Sage Annual Reviews of Communication Research, Communication and Negotiation, ed. Linda L. Putnam \& Michael E. Roloff, Vol. 20, pp. 128-155. Thousand Oaks, CA: Sage Publications.

Rabin, Matthew, and Georg Weizsäcker. 2009. Narrow bracketing and dominated choices. American Economic Review 99: 1508-1543.

Read, Daniel, George Loewenstein, and Matthew Rabin. 1999. Choice Bracketing. Journal of Risk and Uncertainty 19: 171-197.

Redelmeier, Donald A., and D. Kahneman. 1996. Patient's memories of painful medical treatments: Realtime and retrospective evaluations of two minimally invasive procedures. Pain 66: 3-8.

Rothschild, M., and J. Stiglitz. 1970. Increasing Risk I: A Definition. Journal of Economic Theory 2: 225-243.

Rottenstreich, Yuval, and Christopher K. Hsee. 2001. Money, Kisses, and Electircity Shocks: On the Affective Psychology of Risk. Psycological Science 12: 185-190.

Schreiber, Charles A., and Daniel Kahneman. 2000. Determinants of the remembered utility of aversive sounds. Journal of Experimental Psychology 129: 27-42.

Seidl, Christian. 2002. Preference reversal. Journal of Economic Surveys 16: 621-655.

Selten, Reinhard, Abolkrarim Sadrieh, and Klaus Abbink. 1999. Money does not induce risk neutral behaviour but binary lotteries do even worse. Theory and Decision 46: 211-249.

Slovic, Paul, Melissa L. Finucane, Ellen Peters, and Donald G. MacGregor. 2002. The Affect Heuristic. Heuristics and Biases: the Psychology of Intuitive Judgement, 397-420. New York: Cambridge University Press.

Slovic, Paul, Melissa L. Finucane, Ellen Peters, and Donald G. MacGregor. 2004. Risk Analysis and Risk as Feelings: Some Thoughts about Affect, Reason, Risk, and Rationality. Risk Analysis 24 (2): 311-322.

Slovic, Paul, Ellen Peters, Melissa L. Finucane, and Donald G. MacGregor. 2005. Affect, risk and decision making. Health Psychology 24: 35-40.

Starmer, Chris. 1999. Cycling with rules of thumb: An experimental test for a new form of non-transitive behaviour. Theory and Decision 46: 141-158.

Sunstein, Cass R. 2003. Terrorism and Probability Neglect. Journal of Risk and Uncertainty 26: 121-136.

Sunstein, Cass R., and Richard Zeckhauser. 2011. Overreaction to Fearsome Risks. Environmental and Resource Economics 48 (3): 435-449.

Swinburne, Richard. 2005. Bayes' Theorem. Oxford: Oxford University Press. 
Tversky, Amos, and Daniel Kahneman. 1971. Belief in the Law of Small Numbers. Psychlogical Bulletin 76 (2): 105-110.

Tversky, Amos, and Daniel Kahneman. 1973. Availability: A Heuristic for Judging Frequency and Probability. Cognitive Psychology 5 (2): 207-232.

Tversky, Amos, and Daniel Kahneman. 1981. The Framing of Decisions and the Psychology of Choice. Science 211: 453-458.

Tversky, Amos, and Daniel Kahneman. 1983. Extensional Versus Intuitive Reasoning: The Conjunction Fallacy in Probability Judgement. Psychological Review 90: 293-315.

Tversky, Amos, and Daniel Kahneman. 1986. Rational Choice and the Framing of Decisions. The Journal of Business 59: 251-278.

Tversky, Amos, and Daniel Kahneman. 1992. Advances in prospect theory: Cumulative representation of uncertainty. Journal of Risk and Uncertainty 5: 297-323.

Tversky, Amos, and Derek J. Koehler. 1994. Support theory: A nonextensional representation of subjective probability. Psychological Review 101 (4): 547-567.

Varey, Carol, and Daniel Kahneman. 1992. Experiences Extended across Time: Evaluation of Moments and Episodes. Journal of Behavioral Decision Making 5: 169-185.

Viscusi, Kip W., Wesley A. Magat, and Joel Huber. 1987. An Investigation of the Rationality of Consumer Valuations of Multiple Health Risks. The RAND Journal of Economics 18 (4): 465-479.

Wakker, Peter P. 1993. Savage's Axioms Usually Imply Violation of Strict Stochastic Dominance. The Review of Ecoonomic Studies 60: 487-493.

Wakker, Peter P. 2003. The Data of Levy and Levy (2002) "“ Prospect Theory: Much Ado About Nothing? ", Actually Support Prospect Theory. Management Science 49: 979-981.

Wang, Xiao T. 1996. Domain-specific rationality in human choices: violations of utility axioms and social contexts. Cognition 60: 31-63.

Wickham, Philip A. 2003. The representativeness heuristic in judgements involving entrepreneurial success and failure. Management Decision 41: 156-167.

Wu, George, and Gonzalez, Richard. 1999. Dominance violations and event splitting in decision under uncertainty. Unpublished manuscript retrieved from https:/faculty.chicagobooth.edu/george.wu/ papers/dominance.pdf. Accessed 10 Oct 2017

Yacub, Mohammad Zafar, Gohkan Saz, and Hussain Dildar. 2009. A meta analysis of the empirical evidence on expected utility. European Journal of Economics, Finance, and Administrative Sciences 15: $117-133$.

Yamakishi, Kimihiko. 1997. When a $12.86 \%$ Mortality is More Dangerous than $24.14 \%$ : Implications for Risk Communication. Applied Cognitive Psychology 11: 495-506.

Publisher's Note Springer Nature remains neutral with regard to jurisdictional claims in published maps and institutional affiliations. 